\title{
Effects of Exogenous Melatonin on Photosynthetic Characteristics of Eggplant (Solanum melongena L.) under Cadmium Stress
}

\author{
Yi Tang, a , Jingxian $\mathrm{Li}^{2, \mathrm{~b}}$ and Huanxiu $\mathrm{Li}^{1, \mathrm{c}}{ }^{\text {* }}$ \\ ${ }^{1}$ Institute of Pomology and Olericulture, Sichuan Agricultural University, Chengdu, Sichuan, China \\ ${ }^{2}$ College of Horticulture, Sichuan Agricultural University, Chengdu, Sichuan, China \\ tangyisunguochao@sina.com, bjxzbli@163.com, chxli62@163.com \\ ${ }^{*}$ Corresponding author
}

\begin{abstract}
Keywords: Melatonin; Photosynthetic characteristics; Eggplant (Solanum melongena L.); Cadmium stress

Abstract. A pot experiment was conducted to study the effects of exogenous melatonin (MT) on photosynthetic characteristics of eggplant under cadmium $(\mathrm{Cd})$ stress. Five treatments were used in the experiment: leaves were sprayed with $0(\mathrm{CK}), 25,50,100$ and $150 \mu \mathrm{mol} \cdot \mathrm{L}^{-1}$ concentrations of melatonin solution. The results showed that melatonin enhanced net photosynthetic rate (Pn) and transpiration rate ( $\mathrm{Tr})$ of eggplant significantly. With the increasing of melatonin concentration, photosynthetic capacities of eggplant seedlings were enhanced. The result of light use efficiency (LUE), stomatal conductance (Gs) and $\mathrm{CO}_{2}$ concentration of intercellular (Ci) were the same as Pn. Spraying melatonin decreased WUE of eggplant. Therefore, melatonin could use to enhance the photosynthetic ability of eggplant, which would help to improve the adaptability of eggplant, and the best concentration of melatonin was $150 \mu \mathrm{mol} \cdot \mathrm{L}^{-1}$.
\end{abstract}

\section{Introduction}

In recent years, human activities such as industrialization and urbanization, agricultural activities and deficient waste disposal have made soil polluted significantly by heavy metals [1]. Cadmium is one of the most toxic heavy metals in soil, which causes most attention of people [2]. Cadmium can damage the structure and function of plant cell membranes, inhibiting photosynthesis, thus affecting plant growth and development [3-5].

Melatonin (N-acetyl-5-methoxytryptamine) is a naturally occurring indoleamine molecule [6]. In plants, an important role of melatonin is to alleviate the effects of abiotic stresses [7]. Some studies show that melatonin can enhance the photosynthetic ability of plant, especially under stress condition [8-10]. Researchers indicated that melatonin has great prospects in agricultural production [11-12]. In this study, we focused on the effects of melatonin on photosynthetic characteristics of eggplant under $\mathrm{Cd}$ stress. The objectives of this study were to determine whether melatonin could enhance photosynthetic ability of eggplant after Cd exposure.

\section{Materials and Methods}

Materials. Experiments were conducted at Sichuan Agricultural University ( $\left.30^{\circ} 42^{\prime} \mathrm{N}, 103^{\circ} 51^{\prime} \mathrm{E}\right)$, Wenjiang, China. The seeds of eggplant were harvested in 2014 and provided by Zhongdu Seed Company (Chengdu, China). All chemicals used in experiments were of analytical grade. Melatonin was purchased from Sigma-Aldrich (St. Louis, MO, USA).

Experimental Design. The soil samples were air-dried and passed through a 5-mm mesh in July 2015 , and then $3.0 \mathrm{~kg}$ of soil was weighed into each polyethylene pot ( $15 \mathrm{~cm}$ tall, $18 \mathrm{~cm}$ diameter). Cd was added to make a final soil Cd concentration of $10 \mathrm{mg} \cdot \mathrm{kg}^{-1}$ with a saturated heavy metal solution in the form of $\mathrm{CdCl}_{2} \cdot 2.5 \mathrm{H}_{2} \mathrm{O}$. The soils were mixed immediately and again after 4 weeks, during this period soil moisture was kept at $80 \%$. Seeds were sterilized in 5\% sodium hypochlorite solution for 5 min, rinsed in distilled water five times, and were placed on 9-cm-diameter Petri dishes with three 
layers of filter paper moistened with distilled water and germinated at $25 \square$ in darkness. Seeds were considered germinated when the seed coat was broken and a radicle was visible. After germination, seeds were planted in seedling tray filled with nursery substrate. When the third leaf expanded, uniform seedlings were transplanted to polyethylene pots which were prepared before. Seedlings were divided into five groups, and their leaves were sprayed with $0(\mathrm{CK}), 25,50,100,150 \mu \mathrm{mol} \cdot \mathrm{L}^{-1}$ concentrations of melatonin solution. Seedlings were sprayed with melatonin solution every other day, and three times in total. Each treatment consisted of 10 pots with two plant per pot. Positions of the pots were randomly changed daily to minimize positional effects. All experiments were conducted in triplicate. The soil moisture content was maintained at $80 \%$ of field capacity until the plants were harvested. 30 days after the last time of spraying leaves, the photosynthesis of each plant was determined by using LI-6400 portable photosynthesis meter (LI-COR Inc., USA). The photosynthetic parameters of the photosynthesis meter were manual control $\mathrm{CO}_{2}$ concentration $400 \mu \mathrm{mol} \cdot \mathrm{CO}_{2} \mathrm{~mol}^{-1}$, temperature $25 \square$, light intensity $1200 \mu \mathrm{mol} \mathrm{m} \mathrm{m}^{-2} \cdot \mathrm{s}^{-1}$. The determination of photosynthetic parameters were net photosynthetic rate $(\mathrm{Pn})$, transpiration rate $(\mathrm{Tr})$, stomatal conductance $(\mathrm{Gs})$ and $\mathrm{CO}_{2}$ concentration of intercellular $(\mathrm{Ci})$, and each treatment was repeated three times. Water use efficiency $(\mathrm{WUE})=$ net photosynthetic rate $(\mathrm{Pn}) /$ transpiration rate $(\mathrm{Tr})$, Light use efficiency $(\mathrm{LUE})=$ net photosynthetic rate (Pn) / light intensity [13].

Statistic analyses. Statistical analyses were performed using SPSS 13.0 statistical software (IBM, Chicago, IL, USA). Data were analyzed by one-way ANOVA with least significant difference (LSD) at a $5 \%$ confidence level.

\section{Results and Discussion}

Net Photosynthetic Rate (Pn). Compared with CK, melatonin enhanced Pn of eggplant under Cd stress significantly, and the Pn of eggplant was increased with the increasing of MT concentration from $25 \mu \mathrm{mol} \cdot \mathrm{L}^{-1}$ up to $150 \mu \mathrm{mol} \cdot \mathrm{L}^{-1}$ (Fig. 1 ). When the concentration of MT were 25,50 and $100 \mu \mathrm{mol} \cdot \mathrm{L}^{-1}$, these treatments enhanced Pn of eggplant by $41.53 \%(p<0.05), 60.21 \%(p<0.05)$ and $73.19 \%(p<$ $0.05)$ respectively, compared with CK. When the concentration of MT was $150 \mu \mathrm{mol} \cdot \mathrm{L}^{-1}$, Pn of eggplant reached the highest, and increased by $172.86 \%(p<0.05)$. In this study, it was illustrated that melatonin can alleviate the $\mathrm{Cd}$ stress and improving photosynthetic capacity of eggplant seedlings, which was similar with the result obtained in cucumber [14].

Transpiration Rate (Tr). Compared with CK, melatonin increased the Tr of eggplant with the increasing of MT concentration (Fig. 2). Compared with CK, when the concentration of MT was 150 $\mu \mathrm{mol} \cdot \mathrm{L}^{-1}$, Pn of eggplant reached the highest, and increased by $267.69 \%(p<0.05)$. The trend of $\operatorname{Tr}$ was consistent with Pn.

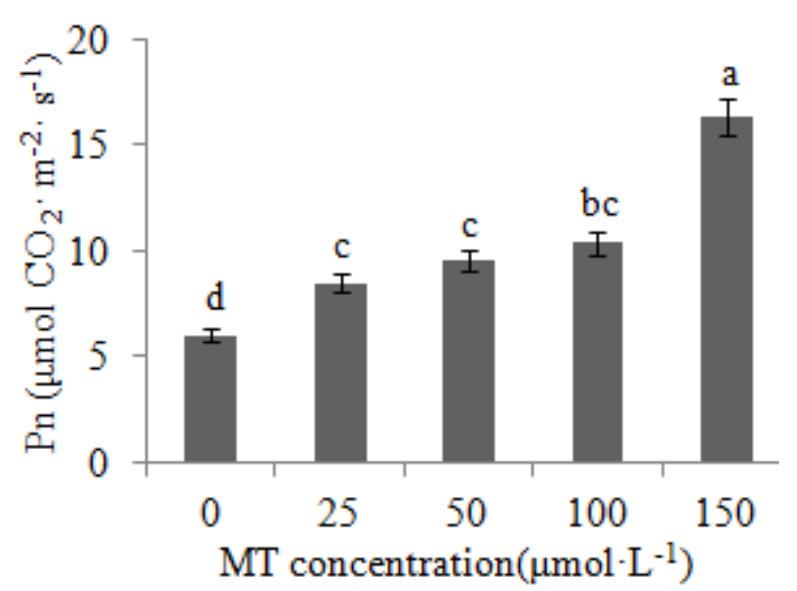

Fig. 1 Pn of MT sprayed eggplant

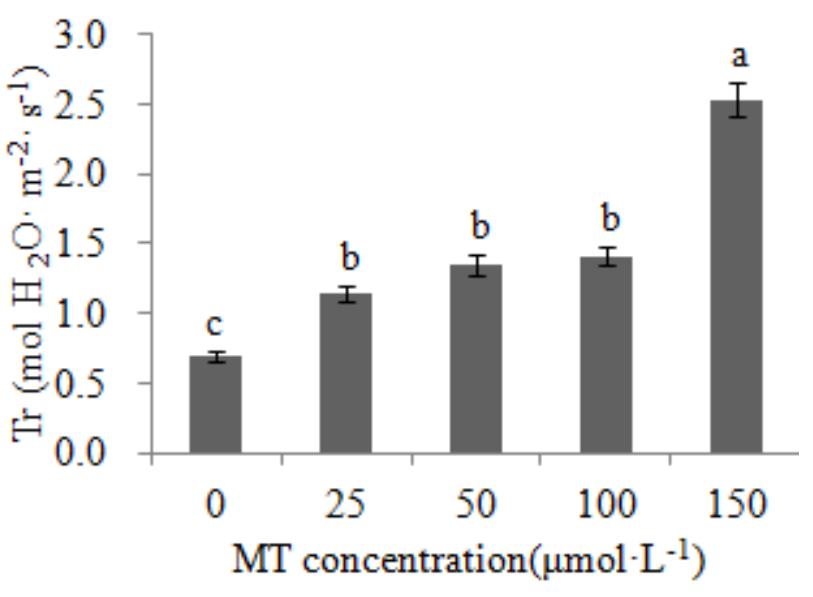

Fig. 2 Tr of MT sprayed eggplant 
Water Use Efficiency (WUE). The Fig. 3 shows that WUE of eggplant decreased by melatonin treatment under Cd stress. Compared with CK, when the concentration of MT were 25, 50, 100 and $150 \mu \mathrm{mol} \cdot \mathrm{L}^{-1}$, these treatments decreased WUE of eggplant by $12.07 \%(p>0.05), 17.92 \%(p<0.05)$, $15.12 \%(p>0.05)$ and $24.98 \%(p<0.05)$, respectively.

Light Use Efficiency (LUE). The same as Pn and Tr, melatonin increased the LUE of eggplant with the increasing of MT concentration under Cd stress (Fig. 4). When the concentration of MT were $25,50,100$ and $150 \mu \mathrm{mol} \cdot \mathrm{L}^{-1}$, these treatments enhanced LUE of eggplant by $41.53 \%(p<0.05)$, $60.21 \%(p<0.05), 73.19 \%(p<0.05)$ and $172.86 \%(p<0.05)$ respectively, compared with CK.

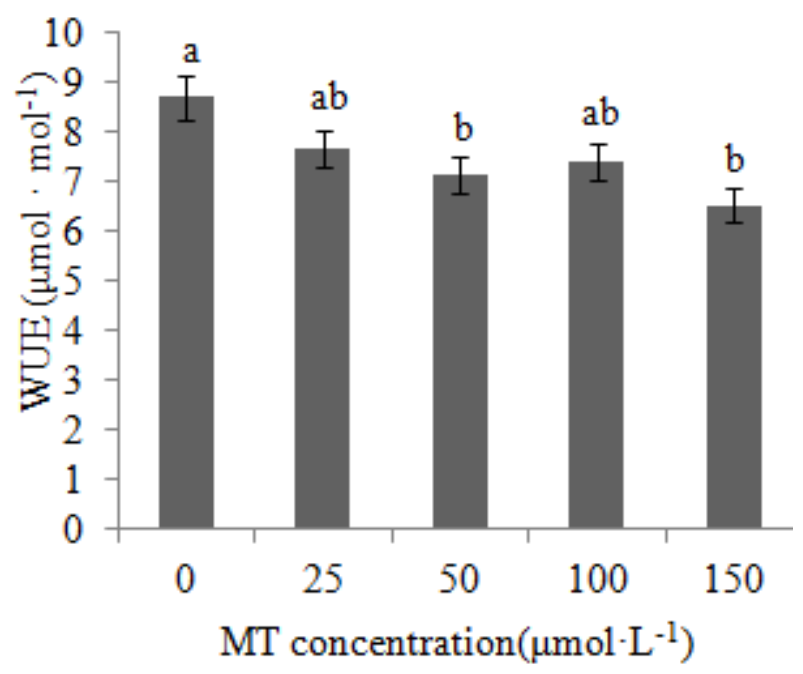

Fig. 3 WUE of MT sprayed eggplant

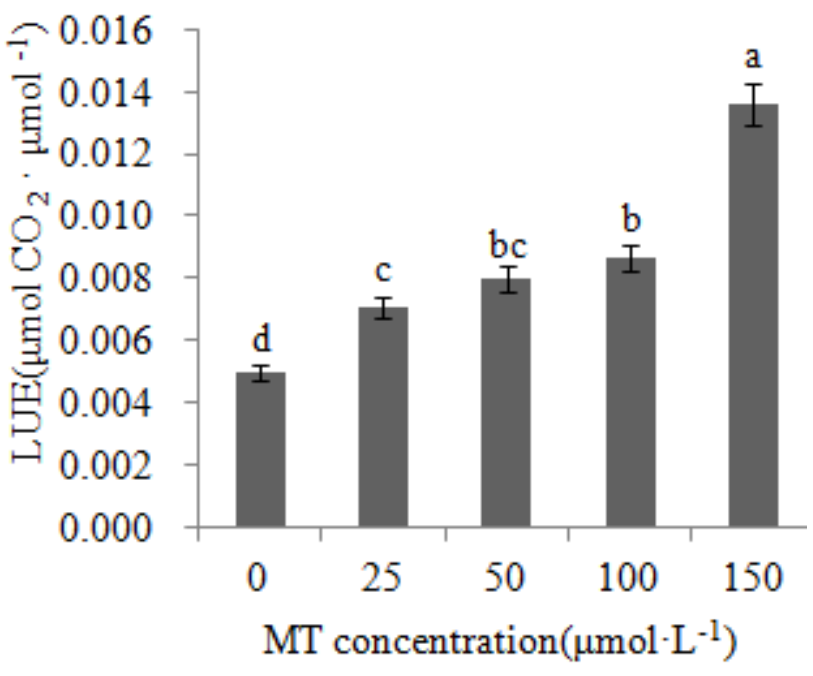

Fig. 4 LUE of MT sprayed eggplant

Stomatal Conductance (Gs). After spraying melatonin, Gs of eggplant increased (Fig. 5), which was consistent with Pn and Tr. The Gs of eggplant was increased with the increasing of MT concentration from $25 \mu \mathrm{mol} \cdot \mathrm{L}^{-1}$ up to $150 \mu \mathrm{mol} \cdot \mathrm{L}^{-1}$. Compared with $\mathrm{CK}$, when the concentration of MT were $25,50,100$ and $150 \mu \mathrm{mol} \cdot \mathrm{L}^{-1}$, these treatments enhanced Gs of eggplant by $78.46 \%(p<0.05)$, $111.88 \%(p<0.05), 119.68 \%(p<0.05)$ and $351.26 \%(p<0.05)$, respectively.

$\mathrm{CO}_{2}$ Concentration of Intercellular $(\mathrm{Ci})$. The same as $\mathrm{Gs}$, after spraying melatonin, Ci of eggplant increased (Fig. 6). The Ci of eggplant reached the highest when the concentration of MT was 150 $\mu \mathrm{mol} \cdot \mathrm{L}^{-1}$. Treatments of different concentration of MT were not significant.

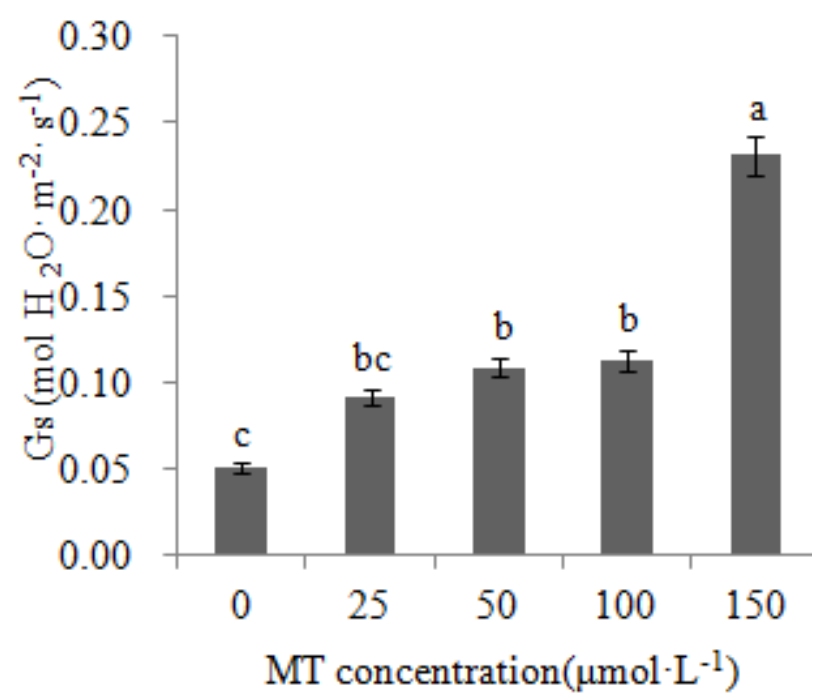

Fig. 5 Gs of MT sprayed eggplant

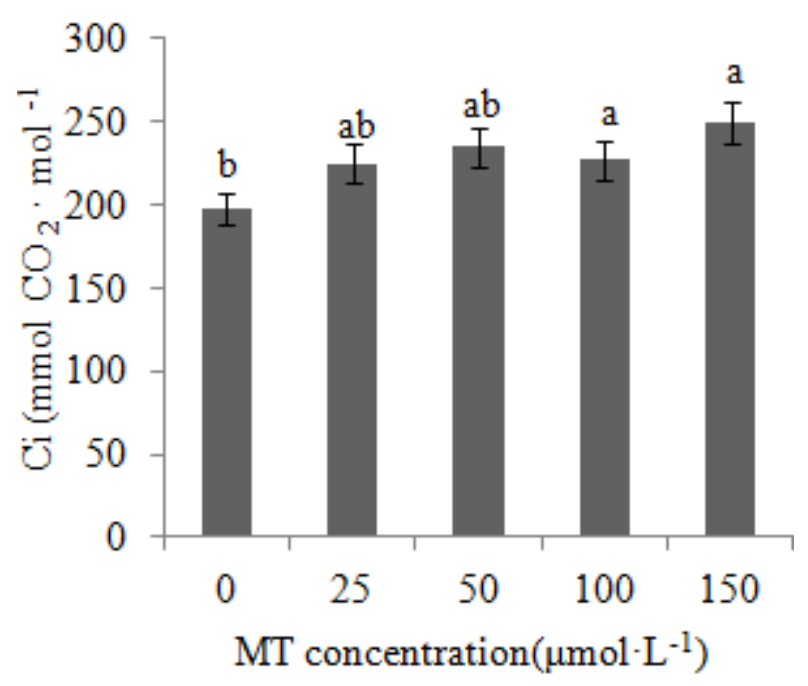

Fig. 6 Ci of MT sprayed eggplant 


\section{Conclusions}

Melatonin can alleviate the Cd stress on photosynthetic organ damage and improving photosynthetic capacity of eggplant seedlings. With the increasing of MT concentration, Pn and Tr of eggplant were enhanced significantly. The result of LUE, Gs and Ci were the same as Pn. Spraying melatonin decreased WUE of eggplant. Therefore, melatonin could use to enhance the photosynthetic ability of eggplant, which would help to improve the adaptability of eggplant.

\section{Acknowledgements}

This work was financially supported by the Sichuan Agricultural University "Shuang-Zhi Plan" Foundation, Sichuan Provincial Department of Education Foundation (15ZA0011).

\section{References}

[1] Y. Sun, Q. Zhou and J. An: Geoderma Vol. 150 (2009), p. 106-112

[2] J.P. Feng, Q.H. Shi and X.F. Wang: Scientia Horticulturae Vol. 123 (2010), p. 521-530

[3] D.T. L Sanità di Toppi, R.Gabbrielli: Environm Exp Bot Vol. 41 (1999), p. 105-130

[4] T.M. Milone, C. Sgherri and H. Clijsters: Environm Exp Bot Vol. 50 (2003), p. 265-276

[5] J. Zhang, Y.C. Liang and Y.S. Lou: Plant Nutrition and Fertilizer Science Vol. 11 (2005), p. 774-780 (In Chinese)

[6] D.X. Tan, R.J. Reiter and L.C. Manchester: Curr Top Med Chem Vol. 2 (2002), p. 181-197

[7] P. Wang, X. Sun and C. Li: J. Pineal Res Vol. 54 (2013), p. 292-302

[8] N. Zhang, B. Zhao and H.J. Zhang: J. Pineal Res Vol. 54 (2013), p. 15-23

[9] L.H. Yin, P. Wang and M.J. Li: J. Pineal Res Vol. 54 (2013), p. 426-434

[10]C. Li, P. Wang and Z. Wei: J. Pineal Res Vol. 53 (2012), p. 298-306

[11]D.X. Tan, R. Hardeland and L.C. Manchester: J. Experimental Botany Vol. 63 (2012), p. 577-597

[12]K.M. Janas, M.M. Posmyk: Acta Physiologiae Plantarum Vol. 35 (2013), p. 3285-3292

[13]X.J. Jiang, H. Wang andW. Peng: Shanxi Journal of Agricultural Sciences Vol. 54 (2008), p. 56-58 (In Chinese)

[14]X.D. Xu, Y. Sun and X.Q. Guo: J. Nuclear Agricultural Sciences Vol. 25 (2011), p. 179-184 